\title{
Effects of Propofol on Endotoxin-Induced Acute Lung Injury in Rabbit
}

This study was undertaken to clarify the effects of propofol on endotoxin-induced acute lung injury. Rabbits were randomly assigned to one of four groups. Each group received intravenous infusion of saline only, saline and Escherichia coli endotoxin, propofol ( $1 \mathrm{mg} / \mathrm{kg}$ bolus, then $5 \mathrm{mg} / \mathrm{kg} / \mathrm{hr}$ ) and endotoxin, or propofol $(4 \mathrm{mg} / \mathrm{kg}$ bolus, then $20 \mathrm{mg} / \mathrm{kg} / \mathrm{hr}$ ) and endotoxin respectively. Infusion of saline or propofol was started $0.5 \mathrm{hr}$ before the infusion of saline or endotoxin, and continued for $6 \mathrm{hr}$ thereafter. The lungs of rabbits were ventilated with $40 \%$ oxygen. Mean blood pressure, heart rate, arterial oxygen tension $\left(\mathrm{PaO}_{2}\right)$, and peripheral blood leukocyte and platelet count were recorded. The wet/dry (W/D) weight ratio of lung and lung injury score were measured, and analysis of bronchoalveolar lavage fluid (BALF) was done. Endotoxin decreased $\mathrm{PaO}_{2}$, and peripheral blood leukocyte and platelet count. And it increased W/D ratio of lung, lung injury score and leukocyte count, percentage of PMN cells, concentration of albumin, thromboxane $\mathrm{B}_{2}$ and IL-8 in BALF. Propofol attenuated all these changes except the leukocyte count in peripheral blood. In conclusion, propofol attenuated endotoxin-induced acute lung injury in rabbits mainly by inhibiting neutrophil and IL-8 responses, which may play a central role in sepsis-related lung injury.

Key Words : Respiratory Distress Syndrome, Adult; Acute Lung Injury; Endotoxins; Propofol

\author{
Sang Hyun Kwak, Jeong II Choi, \\ Jong Tae Park
}

Department of Anesthesiology and Pain Medicine, Department of Legal Medicine*, Chonnam National University, Medical School, Gwangju, Korea

Received: 16 June 2003

Accepted: 16 October 2003

Address for correspondence

Sang Hyun Kwak, M.D.

Assistant Professor in Department of Anesthesiology and Pain Medicine, Chonnam National University,

Medical School, 8 Hakdong, Dong-gu, Gwangju $501-757$, Korea

Tel : +82.62-220-6893, Fax : +82.62-232-6294

E-mail : shkwak@chonnam.ac.kr

\section{INTRODUCTION}

Acute respiratory distress syndrome (ARDS) is a complex syndrome of intense pulmonary inflammatory response with high morbidity and mortality, and is characterized by neutrophil accumulation, interstitial edema, disruption of epithelial integrity, and leakage of protein into the alveolar space that are associated with severe alterations in gas exchange (1). The mortality remains in the range of 30 to $70 \%$, similar to that in seventies when the disease was first described despite recent advances in intensive care (2-4). The most common cause of ARDS is well known to be sepsis $(5,6)$. The precise pathogenesis for sepsis-induced ARDS is not yet fully defined. However, massive accumulation of neutrophils in the lung and increased pulmonary pro-inflammatory cytokines such as tumor necrosis factor-alpha (TNF- $\alpha$ ), interleukin (IL)- $1 \beta$, IL- 6 and IL-8 are major features of ARDS. These mediators have been suggested to play important roles in the initiation and progression of ARDS (7-10). The activation of the neutrophils within the lung causes microvascular injury, attributed to the release of neutrophil proteases and reactive oxygen species $(11,12)$.

Propofol has gained worldwide application not only as an anesthetic agent but also as a sedative agent in the intensive care unit because it can be easily titrated and offers the prospect of rapid recovery. It exerts antioxidant effects $(13,14)$ and resembles the endogenous antioxidant-tocopherol by reacting with free radicals to form a phenoxyl radical in vitro (15). Although most reactive oxygen radicals do not appear to exit cells, propofol exerts a scavenging effect at clinically relevant concentrations on oxidative transformation (16). Propofol affects human neutrophils, and may reduce their participation in the inflammatory damage (17). And it inhibits platelet aggregation without affecting hemostasis in man (18). Propofol suppress IL-8 release from lipopolysaccharide-stimulated neutrophils in vitro (19). These effects of propofol may be advantageous in certain conditions such as acute lung injury due to sepsis.

The major aim of the present study was to evaluate whether these beneficial effects of propofol improve endotoxin-induced acute lung injury in rabbits.

\section{MATERIALS AND METHODS}

Animals

Male albino rabbits, 2.2-2.8 kg of weight, were purchased from Damul Science (Daejeon, Korea). The rabbits were kept on a 12-hr light/dark cycle with free access to food and water. All experiments were conducted in accordance with the insti- 
tutional review board-approved protocols.

\section{General procedure}

Rabbits were initially anesthetized with ketamine hydrochloride $(30 \mathrm{mg} / \mathrm{kg}, \mathrm{i} . \mathrm{m})$ and xylazin hydrochloride $(0.3 \mathrm{mg} /$ $\mathrm{kg}$, i.m). An intravenous angiocatheter was inserted into an ear vein for the route of the administration of fluid and drug. Lactated Ringer's solution was infused at a rate of $8 \mathrm{~mL} / \mathrm{kg} / \mathrm{hr}$ until the end of the study. Tracheostomy was performed aseptically and a 3.5-mm uncuffed endotracheal tube was inserted into the trachea under spontaneous ventilation. After the start of continuous infusion of ketamine $(3 \mathrm{mg} / \mathrm{kg} / \mathrm{hr}$ ) and vecuronium bromide $(0.05 \mathrm{mg} / \mathrm{kg} / \mathrm{hr})$ for maintenance of anesthesia and paralysis of muscle, the lung of the rabbit was mechanically ventilated with $40 \%$ oxygen using a pressure controlled ventilator (Servo 900B, Siemen-Elema, Solna, Sweden). Inspiratory pressure and positive end expiratory pressure (PEEP) were set to $16 \mathrm{cmH}_{2} \mathrm{O}$ and $3 \mathrm{cmH}_{2} \mathrm{O}$ respectively. Respiratory rate was controlled to produce an initial arterial carbon dioxide tension $\left(\mathrm{PaCO}_{2}\right)$ of $35-45 \mathrm{mmH} 2 \mathrm{O}$. The rabbits were placed on a heating pad under a radiant heating lamp to keep body temperature between $36.5^{\circ} \mathrm{C}$ and $37.5^{\circ} \mathrm{C}$ at the esophagus. The arterial catheter was placed in the aorta via carotid artery cut-down to monitor arterial pressure and to harvest blood samples for blood gas analysis and assay. Then we measure baseline values of mean blood pressure, heart rate, peripheral leukocyte and platelet count, and arterial blood gas.

\section{Experimental Protocols}

After the baseline measurements, animals were randomly assigned to one of four groups: saline control group receiving intravenous infusion of saline only (S-S group, $n=7$ ); endotoxin control group receiving intravenous infusion of saline and Escherichia coli endotoxin 0111:B4 (from Sigma Chem Co., St. Louis, Mo, U.S.A.), $5 \mathrm{mg} / \mathrm{kg}$ over $30 \mathrm{~min}$ (S-E group, $\mathrm{n}=7$ ); low-dose propofol treated group receiving intravenous infusion of propofol of $1 \mathrm{mg} / \mathrm{kg}$ bolus followed by $5 \mathrm{mg} / \mathrm{kg} / \mathrm{hr}$ and endotoxin (P5-E group, $\mathrm{n}=7$ ); high-dose propofol treated group receiving intravenous infusion of propofol of $4 \mathrm{mg} / \mathrm{kg}$ bolus followed by $20 \mathrm{mg} / \mathrm{kg} / \mathrm{hr}$ and endotoxin (P20-E group, $\mathrm{n}=7$ ). The dose of propofol was selected according to the reports of low and high dose as sedation in experimental surgery in the rabbit $(20,21)$. The S-E and S-S groups were infused with an equivalent volume of saline instead of propofol.

The infusion of saline or propofol was started $0.5 \mathrm{hr}$ before the infusion of saline or endotoxin and continued during the infusion of saline or endotoxin of $6 \mathrm{hr}$. Arterial blood sample for blood gas analysis, blood cell counts and platelet counts were obtained at $-0.5,0,1,2,3,4,5$, and $6 \mathrm{hr}$ after the start of the infusion of saline or endotoxin. All rabbits were killed $6 \mathrm{hr}$ after the start of the infusion of saline or endotoxin by injection of an overdose of thiamylal. Immediately after the rabbits were killed, the thorax was opened, and the lungs were removed en bloc by observers unaware of the nature of the experiment. The wet weight/dry weight (W/D) ratio of lung and lung injury score of the lung, and number of leukocyte, percent of polymorphonuclear neutrophil (PMN) cells, concentration of albumin, thromboxane $\mathrm{B}_{2}\left(\mathrm{TxB}_{2}\right)$, and IL- 8 in bronchoalveolar lavage fluid (BALF) were measured.

\section{Arterial blood gas analysis and cell counts}

Arterial blood specimens were analyzed for $\mathrm{PaO}_{2}, \mathrm{pH}$, and base excess using blood gas analyzer (GEM Premier Plus, Instrumentation Laboratory, Lexington, MA, U.S.A.). The numbers of peripheral leukocytes and platelets were measured with a cell counter (XE2100, Sysmex, Kobe, Japan).

\section{Lung wet weight to dry weight (W/D) ratio}

The left upper lobe of the lung was weighed and then dried to constant weight at $60^{\circ} \mathrm{C}$ over $48 \mathrm{hr}$ in an oven. To assess tissue edema, the W/D ratio was calculated.

\section{Histopathological examination}

The left lower lobe was fixed by instillation of $10 \%$ glutaraldehyde solution through the left lower bronchus at 20 $\mathrm{cmH}_{2} \mathrm{O}$. The lungs were embedded in paraffin, and the sections were stained with hematoxylin and eosin. Two observers, unaware of the nature of the experiment, scored the lung injury under light microscopy from 0 (no damage) to $4+$ (maximum damage), according to the combined assessment of alveolar congestion, hemorrhage, edema, infiltration/aggregation of neutrophils in the airspace or vessel wall, thickness of the alveolar wall, and hyaline membrane formation.

\section{Preparation of bronchoalveolar lavage fluid}

The BALF was harvested from the right lung. Through the right mainstem bronchus, $35 \mathrm{~mL}$ of saline was infused slowly and withdrawn five times. The saline contained ethylendiamine-tetraacetic acid (EDTA)-2Na and was cooled to $4{ }^{\circ} \mathrm{C}$ to prevent metabolism of leukocytes. Indomethacin was added to the BALF to inhibit further metabolism of arachidonic acid to prostaglandins during analysis. The BALF was analyzed for cell count and cell differentiation.

A cytocentrifuged spin preparation (CF-RD, Sakura, Tokyo, Japan) of the BALF was stained with Wright for cell differentiation. The numbers of leukocytes in the BALF were counted with a cell counter (XE2100, Sysmex, Kobe, Japan). The fluid was then centrifuged at $250 \mathrm{~g}$ at $4{ }^{\circ} \mathrm{C}$ for $20 \mathrm{~min}$ to remove the cells. The cell-free supernatant was divided into several aliquots and stored at $-80^{\circ} \mathrm{C}$ for measurements of various mediators. 


\section{Measurements of mediators in bronchoalveolar lavage fluid}

The following substances, metabolites, and mediators in the BALF were measured. Albumin concentrations were determined by nephrometry with immunogloblin $G$ fraction of goat anti-rabbit albumin (Cappel, Durham, NC, U.S.A.). $\mathrm{TxA} 2$ was quantified by enzyme immunoassay (Amersham, Little Chalfont, U.K.) as TxB2, the stable metabolite of TxA2.

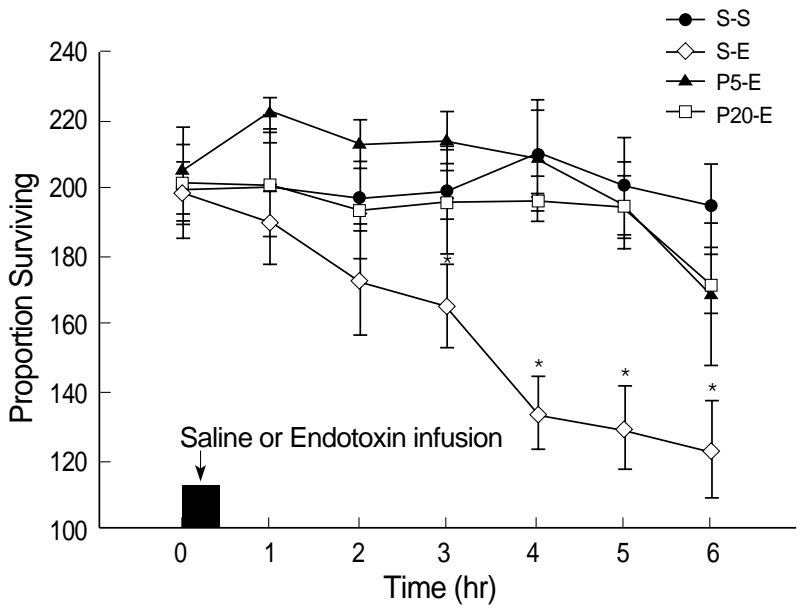

Fig. 1. Comparison of changes in arterial oxygen tension $\left(\mathrm{PaO}_{2}\right)$. S-S, saline control group; S-E, endotoxin control group; P5-E, low dose propofol treated group; P-20E, high dose propofol treated group. Horizontal axis indicates the time period after the start of saline or endotoxin infusion. Each point represents mean \pm SEM of seven rabbits. ${ }^{*} p<0.05$ versus time matched values in $\mathrm{S}-\mathrm{S}$ group.
And the concentration of IL- 8 was measured by enzyme-linked immunosorbent assay (Amersham, Bucks, U.K.). The assay kit cross-reacts with IL- 8 , and rabbit recombinant IL- 8 was used as the standard (22).

\section{Statistical analysis}

Data from experiments are expressed as mean \pm SEM except the lung injury score which is given as a median. Data were statistically analyzed using the following tests for multiple comparisons: two-way repeated measures analysis of variance (ANOVA) followed by Dunnett's test for multiple time points observation, Student's unpaired t-test for single time point observation, and Wilcoxon U-test for histologic data. A value of $p<0.05$ was considered significant.

\section{RESULTS}

\section{Changes in Blood Gas Analysis, Hemodynamics, and Peripheral Blood Leukocyte and Platelet Counts}

The $\mathrm{PaO}_{2}, \mathrm{pH}$, base excess, peripheral blood leukocyte and platelet counts were decreased gradually in S-E group, compared with S-S group. Propofol attenuated the decrease in the $\mathrm{PaO}_{2}$ (Fig. 1). But, the changes in the $\mathrm{pH}$, base excess, and platelet count were attenuated only in P20-E group but not in $\mathrm{P} 5$-E group (Table 1). The $\mathrm{PaCO}_{2}$, mean arterial pressure and heart rate were not significantly changed at any study point in the four groups (data not shown).

Table 1. Changes of $\mathrm{pH}$, base excess, leukocyte and platelet counts in peripheral blood

\begin{tabular}{|c|c|c|c|c|c|c|c|c|}
\hline \multirow{2}{*}{ Variables } & \multicolumn{8}{|c|}{ Time after start of endotoxin or saline infusion } \\
\hline & $-0.5 \mathrm{hr}$ & $0 \mathrm{hr}$ & $1 \mathrm{hr}$ & $2 \mathrm{hr}$ & $3 \mathrm{hr}$ & $4 \mathrm{hr}$ & $5 \mathrm{hr}$ & $6 \mathrm{hr}$ \\
\hline \multicolumn{9}{|l|}{$\mathrm{pH}$} \\
\hline S-S & $7.22 \pm 0.02$ & $7.31 \pm 0.02$ & $7.35 \pm 0.01$ & $7.39 \pm 0.01$ & $7.32 \pm 0.01$ & $7.33 \pm 0.03$ & $7.33 \pm 0.02$ & $7.32 \pm 0.03$ \\
\hline S-E & $7.32 \pm 0.01$ & $7.30 \pm 0.02$ & $7.29 \pm 0.01$ & $7.21 \pm 0.02^{*}$ & $7.16 \pm 0.02^{*}$ & $7.08 \pm 0.05^{\star}$ & $7.05 \pm 0.04^{*}$ & $7.03 \pm 0.04^{*}$ \\
\hline P5-E & $7.33 \pm 0.01$ & $7.34 \pm 0.02$ & $7.30 \pm 0.02$ & $7.11 \pm 0.05^{\star}$ & $7.10 \pm 0.04^{*}$ & $7.07 \pm 0.04^{*}$ & $7.06 \pm 0.04^{*}$ & $7.00 \pm 0.04^{*}$ \\
\hline P20-E & $7.36 \pm 0.02$ & $7.33 \pm 0.02$ & $7.35 \pm 0.03$ & $7.28 \pm 0.02^{*}$ & $7.25 \pm 0.02^{* \dagger}$ & $7.30 \pm 0.02^{* \dagger}$ & $7.27 \pm 0.03^{*^{\dagger}}$ & $7.27 \pm 0.03^{* \dagger}$ \\
\hline \multicolumn{9}{|c|}{ Base Excess (mEq/L) } \\
\hline S-S & $-7.9 \pm 0.3$ & $-8.1 \pm 0.9$ & $-7.1 \pm 1.0$ & $-5.2 \pm 0.8$ & $-8.3 \pm 0.7$ & $-7.5 \pm 0.8$ & $-7.0 \pm 0.6$ & $-7.6 \pm 1.3$ \\
\hline S-E & $-6.8 \pm 1.2$ & $-6.4 \pm 0.5$ & $-7.9 \pm 0.8$ & $-10.1 \pm 0.8^{*}$ & $-12.8 \pm 0.2^{*}$ & $-14.2 \pm 0.5^{*}$ & $-15.6 \pm 0.9^{*}$ & $-16.3 \pm 1.1^{*}$ \\
\hline P5-E & $-9.8 \pm 1.3$ & $-10.9 \pm 1.2$ & $-11.1 \pm 0.6$ & $-16.2 \pm 1.4^{*}$ & $-14.9 \pm 1.4^{*}$ & $-16.4 \pm 1.3^{*}$ & $-16.4 \pm 1.6^{*}$ & $-17.3 \pm 1.2^{*}$ \\
\hline P20-E & $-8.8 \pm 1.2$ & $-8.4 \pm 1.4$ & $-9.2 \pm 1.2$ & $-11.4 \pm 1.2^{*}$ & $-12.0 \pm 1.6^{*}$ & $-10.2 \pm 1.1^{* \dagger}$ & $-12.0 \pm 1.4^{* \dagger}$ & $-8.8 \pm 0.9^{\dagger}$ \\
\hline \multicolumn{9}{|c|}{ Leukocytes ( $\left.\times 10^{2} / \mu \mathrm{L}\right)$} \\
\hline S-S & $44 \pm 2$ & $47 \pm 2$ & $44 \pm 4$ & $48 \pm 4$ & $49 \pm 4$ & $48 \pm 5$ & $44 \pm 3$ & $45 \pm 2$ \\
\hline S-E & $52 \pm 6$ & $50 \pm 6$ & $26 \pm 5^{*}$ & $20 \pm 2^{*}$ & $16 \pm 2^{*}$ & $14 \pm 2^{*}$ & $13 \pm 2^{*}$ & $14 \pm 2^{*}$ \\
\hline P5-E & $53 \pm 4$ & $55 \pm 6$ & $27 \pm 5^{*}$ & $21 \pm 2^{*}$ & $9 \pm 2^{*}$ & $13 \pm 4^{*}$ & $17 \pm 7^{*}$ & $10 \pm 1^{*}$ \\
\hline P20-E & $46 \pm 3$ & $50 \pm 5$ & $23 \pm 2^{*}$ & $23 \pm 2^{\star}$ & $11 \pm 2^{\star}$ & $10 \pm 1^{*}$ & $11 \pm 1^{*}$ & $11 \pm 1^{*}$ \\
\hline \multicolumn{9}{|c|}{ Platelets $\left(\times 10^{3} / \mu \mathrm{L}\right)$} \\
\hline S-S & $232 \pm 14$ & $235 \pm 17$ & $240 \pm 13$ & $241 \pm 19$ & $240 \pm 21$ & $228 \pm 16$ & $242 \pm 22$ & $239 \pm 24$ \\
\hline S-E & $252 \pm 29$ & $240 \pm 30$ & $119 \pm 35^{*}$ & $138 \pm 44^{*}$ & $102 \pm 21^{*}$ & $97 \pm 33^{*}$ & $64 \pm 21^{*}$ & $83 \pm 36^{*}$ \\
\hline P5-E & $268 \pm 26$ & $268 \pm 26$ & $155 \pm 29^{*}$ & $153 \pm 33^{*}$ & $153 \pm 31^{*}$ & $133 \pm 17^{*}$ & $130 \pm 16^{*}$ & $126 \pm 30^{*}$ \\
\hline P20-E & $265 \pm 22$ & $272 \pm 19$ & $209 \pm 10^{*^{\dagger}}$ & $205 \pm 17^{*^{\dagger}}$ & $181 \pm 10^{*^{\dagger}}$ & $145 \pm 12^{*^{\dagger}}$ & $161 \pm 13^{*}$ & $147 \pm 16^{*^{\dagger}}$ \\
\hline
\end{tabular}

Values are mean \pm SEM. ${ }^{*} p<0.05$ versus group $S-S,{ }^{\dagger} p<0.05$ for group P5-E or P20-E versus group S-E. 


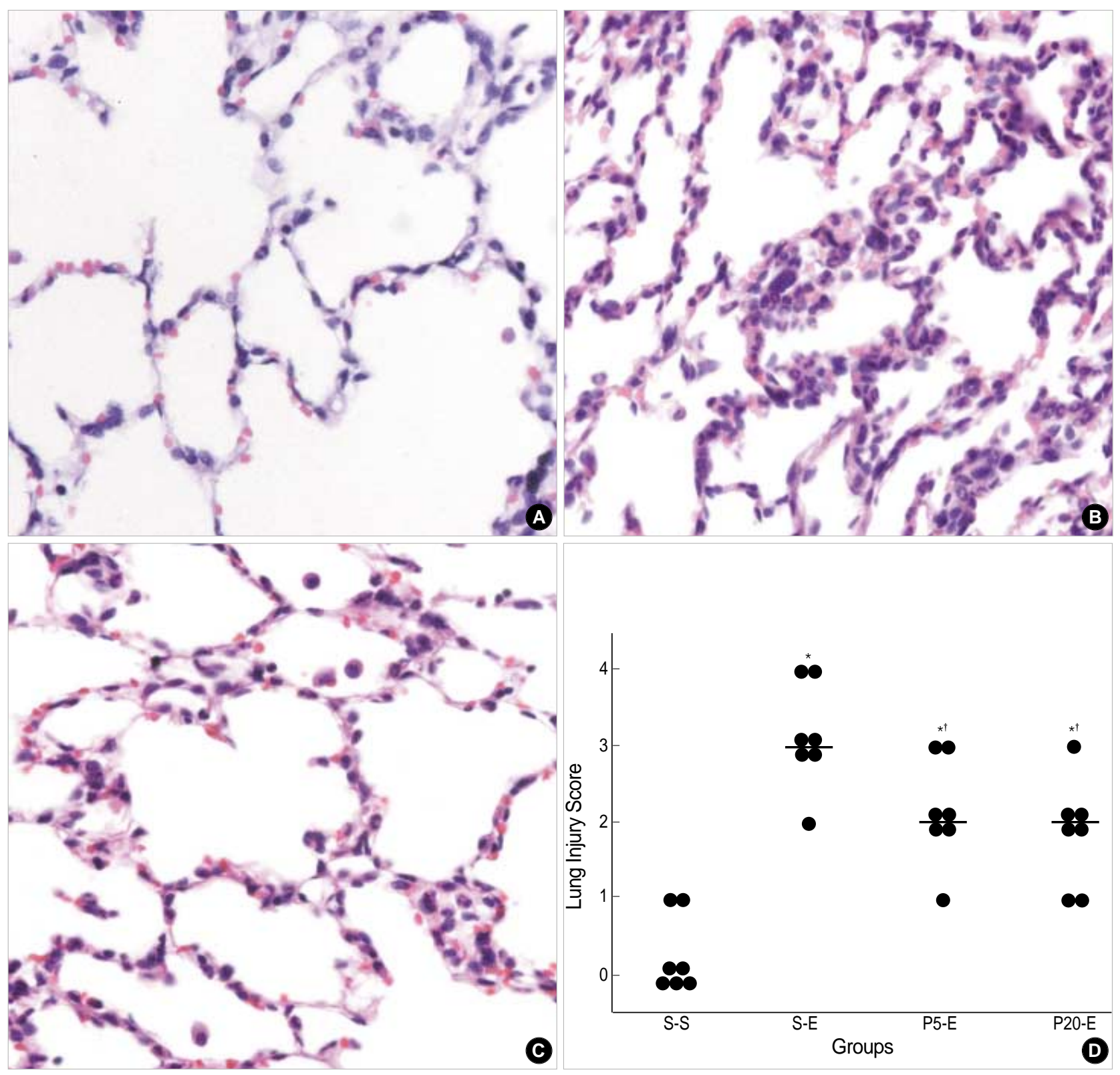

Fig. 2. Effects of propofol on lung tissue damage $6 \mathrm{hr}$ after the start of saline or endotoxin infusion. Representive photomicrographs show rabbit's lung with median values of lung injury score in (A) group S-S, (B) group S-E, and (C) group P-E (H\&E, $\times 400)$. Lung injury score (D) was recorded from 0 (no damage) to 4+ (maximum damage) according to the criteria described in Materials and Methods. Each bar represents median value of seven rabbits in each group. ${ }^{\star} p<0.05$ versus group S-S. ${ }^{\dagger} p<0.05$ for group P5-E or P20-E versus group S-E.

\section{Analysis of Bronchoalveolar Lavage Fluid}

The percentage of BALF recovered from the four groups was $77 \%$ to $85 \%$. This range of percentages indicates a similar dilution among the animals. Notably more leukocytes in BALF were recovered in S-E group than those in S-S group, suggesting that the neutrophils marginating to the pulmonary capillary endothelium had infiltrated into alveolar spaces from peripheral blood. And propofol slightly attenuated the increase in leukocyte counts in BALF (Table 2).
Differential counts revealed that leukocytes of the BALF in $\mathrm{S}$-S group were mostly macrophages. In contrast, the percentage of polymorphonuclear neutrophils in the BALF markedly increased in S-E group in which the mean percentage of polymorphonuclear neutrophils was as high as $8 \%$. Propofol significantly attenuated the increase in this percentage (Table 2).

The concentrations of albumin, $\mathrm{TxB}_{2}$ and IL- 8 in the BALF were increased in S-E group, compared with S-S group. Propofol attenuated the increase dose-dependently (Table 2). 
Table 2. Analysis of bronchoalveolar lavage fluids (BALF) and wet to dry (W/D) weight ratio

\begin{tabular}{|c|c|c|c|c|}
\hline Variables & S-S & S-E & P5-E & P20-E \\
\hline Leukocyte count & $185 \pm 89$ & $514 \pm 146^{*}$ & $428 \pm 188^{*^{\dagger}}$ & $400 \pm 129^{* \dagger}$ \\
\hline$\%$ PMN & $3.04 \pm 0.25$ & $8.91 \pm 0.53^{*}$ & $5.14 \pm 0.56^{*^{\dagger}}$ & $3.86 \pm 0.32$ \\
\hline Albumin (mg/dL) & $1.2 \pm 0.3$ & $8.9 \pm 1.1^{*}$ & $4.5 \pm 0.6^{\star^{\dagger}}$ & $2.3 \pm 0.5^{\ddagger}$ \\
\hline IL-8 (fmol/mL) & $1 \pm 0.4$ & $13 \pm 3^{*}$ & $6 \pm 0.8^{*^{\dagger}}$ & $3 \pm 1^{\star \ddagger}$ \\
\hline $\mathrm{TxB}_{2}(\mathrm{pg} / \mathrm{mL})$ & $104 \pm 29$ & $219 \pm 54^{*}$ & $187 \pm 38^{*}$ & $157 \pm 32^{* \dagger}$ \\
\hline W/D ratio & $2.03 \pm 0.19$ & $3.89 \pm 0.44^{*}$ & $2.95 \pm 0.36^{* \dagger}$ & $2.64 \pm 0.50^{\ddagger}$ \\
\hline
\end{tabular}

Values are mean \pm SEM. PMN, polymorphonuclear neutrophil; IL-8, Interleukin-8; TxB2, Thromboxane B. ${ }^{*} p<0.05$ versus group S-S, ${ }^{\dagger} p<0.05$ for group P5-E or P20-E versus group S-E, ${ }^{\ddagger} p<0.01$ for group P5-E or P2OE versus group S-E.

\section{Lung Wet/Dry Weight Ratio}

The wet/dry weight ratio was increased in S-E group, compared with S-S group. Propofol attenuated the increase in this ratio dose-dependently (Table 2 ).

\section{Histopathologic Grading}

Light microscopic findings in S-E group include edema, hemorrhage, thickening of the alveolar wall, and infiltration of inflammatory cells into alveolar spaces. In contrast, these changes were less prominent in the rabbits receiving propofol. Assessment of the lung injury scores demonstrated that propofol successfully reduced the histopathologic severity of the lung injury (Fig. 2).

\section{DISCUSSION}

The main findings of the present experiments were propofol attenuated the deterioration in oxygenation, pulmonary edema (as assessed by increase in the W/D ratio and the concentrations of albumin in the BALF), pro-inflammatory cytokine (IL-8) and neutrophil responses and histologic alteration induced by endotoxin.

Acute respiratory distress syndrome (ARDS) due to endotoxin-induced acute lung injury is a complex syndrome of intense pulmonary inflammatory responses characterized by neutrophil accumulation, interstitial edema, disruption of epithelial integrity and leakage of protein into the alveolar space, and associated with severe alterations in gas exchange (1).

Several plausible mechanisms responsible for endotoxininduced acute lung injury have been proposed, but the precise one remains to be determined. Various inflammatory mediators have been found in the blood and the BALF of the patients with ARDS, which include neutrophils, cytokines/ chemokines, lipid mediators (phospholipase $A_{2}$, thromboxane $A_{2}$, prostacyclin), and platelet activating factor $(23,24)$. It is suggested that these mediators play important roles in the initiation and progression of acute lung injury and ARDS.
Endotoxin causes the activation of alveolar macrophage, which releases cytokines such as TNF- $\alpha$, IL-1, IL-6, and IL8 . These substances promote the chemotaxis and adherence of neutrophils to pulmonary vascular endothelium by enhancing the expression of adhesive molecules on endothelial membranes $(25,26)$. It also activates complements, which results in liberation of active fragments such as C3a and C5a. These activated fragments are chemotactic and aggregating factors for neutrophils (27).

Activated neutrophils adherent to the pulmonary vascular endothelium through adhesion molecules attack the endothelium by releasing proteases, reactive oxygen species and arachidonic acid metabolites, particularly TxA2. These substances mediate bronchoconstriction and pulmonary vasoconstriction, and increase capillary permeability causing pulmonary edema. And platelet-activating factor is released from neutrophil and causes platelet-mediated lung edema in isolated rabbit lung (27-29). Platelets also have the potential to cause lung injury by the release of various compounds found in their granules, including serotonin, lysosomal enzymes, and $\mathrm{TxB}_{2}(30)$. In this process, platelets are activated, aggregated and trapped as microemboli in the pulmonary capillaries. However, neutrophil and proinflammatory cytokines have been regarded as double-edged swords in sepsis. Although they are thought to be essential for the eradication of pathogens, excessive release of them was also believed to be responsible for injury to organs. So, the balances of the activation and intrapulmonary sequestration of them may be important for the development of lung injury.

In the present study, the extent of increase of lung W/D ratio, albumin concentrations in BALF and histologic alteration in the rabbits with endotoxemia were reduced by propofol. It is a very important finding because these parameters are indexes for the pulmonary edema due to vascular endothelial permeability disorder.

Neutrophil aggregation and inflammatory mediators produced by activated neutrophils such as granulocyte elastase and superoxide radical are believed to be involved in pulmonary vascular injury (31). Furthermore, reactive oxygen species inactivates antiproteases and enhances the susceptibility of microvasculature to neutrophil elastase contributing indirectly to edematous lung injury (27).

Basu et al. have shown that propofol reduced the lipid peroxidation significantly, which is endotoxin-induced, free radical mediated and cyclooxygenase catalysed (32). Inada et al. also found that propofol depressed neutrophil hydrogen peroxide production in rat with abdominal sepsis (33).

Although plasma or BALF concentrations of hydrogen peroxide were not determined in our study, stopping of the series of events by propofol may be responsible for the attenuation of plasma platelet aggregation and neutrophil sequestration into the lung. So the implications are that propofol counteracts endotoxin-induced deterioration of arterial oxygenation and pulmonary edema. 
Several studies on the effect of propofol on the plasma cytokine have been reported. Crozier et al. found that pro-inflammatory cytokine (IL-6) production after abdominal hysterectomy was suppressed and delayed in patients receiving total intravenous anesthesia with propofol and alfentanil (34). Galley et al. reported that propofol suppressed IL-8 release from lipopolysaccharide-stimulated neutrophils in vitro (19). Taniguchi et al. also reported that propofol attenuated plasma cytokine response (IL-6) to endotoxemia in rat (35). In the present study, increases in the BALF concentrations of IL-8 in the propofol-endotoxemia group were significantly lower than those in the endotoxemia group. This finding confirmed that even in a BALF, propofol has an inhibitory effect on the cytokine response to endotoxemia. Above findings also suggest that the absence of an increase in cytokines may have helped attenuate the deterioration of oxygenation and pulmonary edema in the propofol-endotoxemia group.

In this study, the increase in the percent of polymorphonuclear neutrophil cells in BALF was attenuated dose-dependently in propofol-endotoxemia group and so it is likely that propofol suppressed the accumulation of neutrophils in the lung, although concentrations of chemotaxins inducing sequestration of neutrophil in BALF were not measured. Several investigators reported the inhibition of neutrophil functions by propofol in vitro. Mikawa et al. have shown that propofol inhibits phagocytic function and reactive oxygen species production of neutrophil (17). Inada et al. also reported that propofol and midazolam depressed neutrophil hydrogen peroxide production by blood neutrophils at clinical concentrations in sepsis (32). The findings of our study are consistent with those results and confirmed that even in in vivo experiment, propofol inhibited neutrophil functions in response to endotoxemia.

In the present experiments, high dose propofol attenuated the decrease in blood platelet count in rabbits with endotoxemia. This finding suggested that propofol has an inhibiting effect on platelet aggregation. Hirakata et al. reported that propofol has both enhancing and suppressing effects on human platelet aggregation in vitro (36). According to this report, low concentration of propofol $(40 \mu \mathrm{M})$ enhanced the adenosine diphosphate- and epinephrine-induced secondary platelet aggregation, whereas high concentration of propofol $(100 \mu \mathrm{M})$ suppressed it. Aoki et al. reported that propofol inhibited platelet aggregation both in vivo and in vitro (18). Inhibition of platelet aggregation appeared to be caused by propofol itself and not by the fat emulsion. This inhibitory effect was also supported by the suppressed influx and discharge of calcium. De La Cruz et al. showed that propofol inhibits cellular oxidative damage measured in platelets from surgical patients (37). These reports are consistent with the result of the present study, in which high dose propofol has an inhibiting effect on platelet aggregation.

The pathogenesis of endotoxin-induced lung injury is complicated and the final step of this injury is thought to be the release of reactive oxygen species, proteases, or arachidonic acid metabolites by activated leukocytes, macrophages, and platelets, leading to the attack against endothelium or epithelium and high permeability edema. It takes several hours to activate macrophages, neutrophils, platelets, endothelial cells, and other cells by various mediators such as cytokines and activated complements. Therefore, early continuous infusion of propofol possibly targets this final step to attenuate lung injury.

Critically ill patients with ARDS due to sepsis and septic shock suffer a high degree of stress because of pain and anxiety and the organ-specific responses to sepsis. One of the important objectives in the management of these patients is to achieve an adequate level of sedation. Although the need for adequate sedation in septic patients is generally accepted, there is no consensus regarding which drugs should be used.

We believe that propofol has an advantage of preventing inflammatory effects in sedation for patients with ARDS due to sepsis. However, further studies are required to determine the effects of treatment with propofol over a longer period and the optimal dose when the drug is given alone as a therapy for the patients with ARDS.

\section{REFERENCES}

1. Kollef MH, Schuster DP. The acute respiratory distress syndrome. N Engl J Med 1995; 332: 27-37.

2. Bernard GR, Artigas A, Brigham KL, Carlet J, Falke K, Hudson L, Lamy M, Legall JR, Morris A, Spragg R. The American-European Consensus Conference on ARDS. Definitions, mechanisms, relevant outcomes, and clinical trial coordination. Am J Respir Crit Care Med 1994; 149: 818-24.

3. Sloane PJ, Gee MH, Gottlieb JE, Albertine KH, Peters SP, Burns JR, Machiedo G, Fish JE. A multicenter registry of patients with acute respiratory distress syndrome. Physiology and outcome. Am Rev Respir Dis 1992; 146: 419-26.

4. Vasilyev S, Schaap RN, Mortensen JD. Hospital survival rates of patients with acute respiratory failure in modern respiratory intensive care units. An international, multicenter, prospective survey. Chest 1995; 107: 1083-8.

5. Knaus WA, Sun X, Hakim RB, Wagner DP. Evaluation of definitions for adult respiratory distress syndrome. Am J Respir Crit Care Med 1994; 150: 311-7.

6. Repine JE. Scientific perspective on adult respiratory distress syndrome. Lancet 1992; 339: 466-9.

7. Chollet-Martin S, Jourdain B, Gibert C, Elbim C, Chastre J, GougerotPocidalo MA. Interactions between neutrophils and cytokines in blood and alveolar spaces during ARDS. Am J Respir Crit Care Med 1996; 154: 594-601.

8. Goodman RB, Strieter RM, Martin DP, Steinberg KP, Milberg JA, Maunder RJ, Kunkel SL, Walz A, Hudson LD, Martin TR. Inflammatory cytokines in patients with persistence of the acute respiratory distress syndrome. Am J Respir Crit Care Med 1996; 154: 602-11.

9. Suter PM, Suter S, Girardin E, Roux-Lombard P, Grau GE, Dayer JM. 
High bronchoalveolar levels of tumor necrosis factor and its inhibitors, interleukin-1, interferon, and elastase, in patients with adult respiratory distress syndrome after trauma, shock, or sepsis. Am Rev Respir Dis 1992; 145: 1016-22.

10. Jacobs RF, Tabor DR, Burks AW, Campbell GD. Elevated interleukin1 release by human alveolar macrophages during the adult respiratory distress syndrome. Am Rev Respir Dis 1989; 140: 1686-92.

11. Okumura Y, Inoue H, Fujiyama Y, Bamba T. Effects of serine protease inhibitors on accumulation of polymorphonuclear leukocytes in the lung induced by acute pancreatitis in rats. J Gastroenterol 1995; 30: 379-86.

12. McCord JM, Gao B, Leff J, Flores SC. Neutrophil-generated free radicals: possible mechanisms of injury in adult respiratory distress syndrome. Environ Health Perspect 1994; 102 (Suppl 10): 57-60.

13. Murphy PG, Bennett JR, Myers DS, Davies MJ, Jones JG. The effect of propofol anaesthesia on free radical-induced lipid peroxidation in rat liver microsomes. Eur J Anaesthesiol 1993; 10: 261-6.

14. Mathy-Hartert M, Deby-Dupont G, Hans P, Deby C, Lamy M. Protective activity of propofol, Diprivan and intralipid against active oxygen species. Mediators Inflamm 1998; 7: 327-33.

15. Murphy PG, Myers DS, Davies MJ, Webster NR, Jones JG. The antioxidant potential of propofol (2,6-diisopropylphenol). Br J Anaesth 1992; 68: 613-8.

16. Heine J, Leuwer M, Scheinichen D, Arseniev L, Jaeger K, Piepenbrock S. Flow cytometry evaluation of the in vitro influence of four i.v. anaesthetics on respiratory burst of neutrophils. Br J Anaesth 1996; 77: 387-92.

17. Mikawa K, Akamatsu H, Nishina K, Shiga M, Maekawa N, Obara H, Niwa Y. Propofol inhibits human neutrophil functions. Anesth Analg 1998; 87: 695-700.

18. Aoki H, Mizobe T, Nozuchi S, Hiramatsu N. In vivo and in vitro studies of the inhibitory effect of propofol on human platelet aggregation. Anesthesiology 1998; 88: 362-70.

19. Galley HF, Dubbels AM, Webster NR. The effect of midazolam and propofol on interleukin-8 from human polymorphonuclear leukocytes. Anesth Analg 1998; 86: 1289-93.

20. Perez-Martinez A, Gonzalvez-Pinera J, Marco-Macian A, CarpinteroMoreno F, Moya-Marchante M. [Propofol in continuous perfusion as anesthetic in experimental surgery in the rabbit.] Rev Esp Anestesiol Reanim 1995; 42: 253-6.

21. Ichinohe T, Aida H, Kaneko Y. Interaction of nitrous oxide and propofol to reduce hypertensive response to stimulation. Can J Anaesth 2000; 47: 699-704.

22. Matsukawa A, Yoshimura T, Miyamoto K, Ohkawara S, Yoshinaga M. Analysis of the inflammatory cytokine network among TNF alpha, IL-1 beta, IL-1 receptor antagonist, and IL-8 in LPS-induced rabbit arthritis. Lab Invest 1997; 76: 629-38.

23. Demling RH. Adult respiratory distress syndrome: current concepts. New Horiz 1993; 1: 388-401.

24. Touqui L, Arbibe L. A role for phospholipase A2 in ARDS pathogenesis. Mol Med Today 1999; 5: 244-9.

25. Brigham KL, Meyrick B. Endotoxin and lung injury. Am Rev Respir Dis 1986; 133: 913-27.

26. Bernard C, Tedgui A. Cytokine network and the vessel wall. Insights into septic shock pathogenesis. Eur Cytokine Netw 1992; 3: 19-33.

27. Lamy M, Deby-Dupont G, Deby C, Pincemail J, Duchateau J, Braun M, Damas P, Roth M. Measurements of mediator cascade during adult respiratory distress syndrome. In: Artigs A, Lemaire F, Suter PM, Zapol WM, Adult Respiratory Distress Syndrome. New York: Churchill Livingstone, 1992; 71-88.

28. Samuelsson B, Dahlen SE, Lindgren JA, Rouzer CA, Serhan CN. Leukotrienes and lipoxins: structures, biosynthesis, and biological effects. Science 1987; 237: 1171-6.

29. Spragg RG. Platelets and acute lung injury. In: Artigs A, Lemaire F, Suter PM, Zapol WM, Adult Respiratory Distress Syndrome. New York: Churchill Livingstone, 1992; 89-94.

30. Christman BW, Lefferts PL, Blair IA, Snapper JR. Effect of plateletactivating factor receptor antagonism on endotoxin-induced lung dysfunction in awake sheep. Am Rev Respir Dis 1990; 142: 1272-8.

31. Glauser FL, Fairman RP. The uncertain role of the neutrophil in increased permeability pulmonary edema. Chest 1985; 88: 601-7.

32. Basu S, Mutschler DK, Larsson AO, Kiiski R, Nordgren A, Eriksson MB. Propofol (Diprivan-EDTA) counteracts oxidative injury and deterioration of the arterial oxygen tension during experimental septic shock. Resuscitation 2001; 50: 341-8.

33. Inada T, Taniuchi S, Shingu K, Kobayashi Y, Fujisawa J, Nakao S. Propofol depressed neutrophil hydrogen peroxide production more than midazolam, whereas adhesion molecule expression was minimally affected by both anesthetics in rats with abdominal sepsis. Anesth Analg 2001; 92: 437-41.

34. Crozier TA, Muller JE, Quittkat D, Sydow M, Wuttke W, Kettler D. Effect of anaesthesia on the cytokine responses to abdominal surgery. Br J Anaesth 1994; 72: 280-5.

35. Taniguchi T, Yamamoto K, Ohmoto N, Ohta K, Kobayashi T. Effects of propofol on hemodynamic and inflammatory responses to endotoxemia in rats. Crit Care Med 2000; 28: 1101-6.

36. Hirakata H, Nakamura K, Yokubol B, Toda H, Hatano Y, Urabe N, Mori K. Propofol has both enhancing and suppressing effects on human platelet aggregation in vitro. Anesthesiology 1999; 91: 1361-9.

37. De La Cruz JP, Zanca A, Carmona JA, de la Cuesta FS. The effect of propofol on oxidative stress in platelets from surgical patients. Anesth Analg 1999; 89: 1050-5. 